This item was submitted to Loughborough's Research Repository by the author.

Items in Figshare are protected by copyright, with all rights reserved, unless otherwise indicated.

\title{
An experience sampling study of organizational stress processes and future playing time in professional sport
}

PLEASE CITE THE PUBLISHED VERSION

https://doi.org/10.1080/02640414.2020.1717302

PUBLISHER

Taylor \& Francis

VERSION

AM (Accepted Manuscript)

PUBLISHER STATEMENT

This is an Accepted Manuscript of an article published by Taylor \& Francis in Journal of Sports Sciences on 28 Jan 2020, available online: http://www.tandfonline.com/10.1080/02640414.2020.1717302.

\section{LICENCE}

CC BY-NC-ND 4.0

\section{REPOSITORY RECORD}

Rumbold, James, David Fletcher, and Kevin Daniels. 2020. "An Experience Sampling Study of Organizational Stress Processes and Future Playing Time in Professional Sport". Loughborough University. https://hdl.handle.net/2134/14223110.v1. 
1 An Experience Sampling Study of Organizational Stress Processes and

2 Future Playing Time in Professional Sport

3 James L. Rumbold ${ }^{1}$, David Fletcher ${ }^{2}, \&$ Kevin Daniels ${ }^{3}$

$4{ }^{1}$ College of Health, Wellbeing and Life Sciences, Sheffield Hallam University, Sheffield,

$5 \quad$ United Kingdom. Email: J.Rumbold@shu.ac.uk. Orchid ID: 0000-0002-1914-1036

$6 \quad{ }^{2}$ School of Sport, Exercise and Health Sciences, Loughborough University,

7 Loughborough, United Kingdom. Email: D.Fletcher@lboro.ac.uk. Orchid ID:0000-

8 0002-0556-0360

$9 \quad{ }^{3}$ Norwich Business School, University of East Anglia, Norwich, United Kingdom.

10 Email: Kevin.Daniels@uea.ac.uk.Orchid ID:0000-0002-8620-886X

11

12 Corresponding Author: Dr James L. Rumbold, College of Health, Wellbeing and Life

13 Sciences, Sheffield Hallam University, Collegiate Crescent, Sheffield, S10 2BP, United

14 Kingdom.

15

16

17

18

19

20

21

22 Word Count: 5863

23 Tables: 2

24 Figures: 0 


\section{An Experience Sampling Study of Organizational Stress Processes and 26 Future Playing Time in Professional Sport}

This study examined the relationships between daily cognitive appraisals of organizational events, affective responses and coping. In addition, a five-year longitudinal relationship between coping and performance outcomes at the senior professional level was assessed. Using an experience sampling method, professional academy rugby union players $\left(N=39, M_{\text {age }}=17.23\right.$ years, $S D=$ $0.87)$ completed daily diary measures of appraisals, affective responses, and coping over five weeks of training. Hierarchical linear modeling revealed that daily cognitive appraisals were related to daily affective responses and coping functions enacted by behaviours, after accounting for a series of within- (e.g., time, day, week) and between-person (e.g., personality, key decision makers) differences. Zero-inflated negative binomial regression revealed that coping related to eliciting support was associated with minutes played at the senior professional level five years later. This study extends theoretical knowledge of the within- and between-person relationships that explain organizational stress experiences. The findings suggest that some coping functions enacted by behaviours may be early indicators of future performance outcomes in professional sport.

Keywords: Appraisals; coping; diary methods; multilevel; performance; personality 


\section{Introduction}

Organizational stress is a dynamic and adaptational process. This is characterised by a transaction between an individual and the environmental demands associated with the organization in which they are operating (Fletcher, Hanton, \& Mellalieu, 2006). Integral to this conceptualisation are a person's cognitive appraisals of events, affective responses and coping efforts, which interact to mediate the stress process (Lazarus, 1991a). In so far that these mediating processes underline the meanings that individuals give to environmental situations, it has been argued that the relationships between these variables may also be independent of the environment demand encountered (Folkman \& Lazarus, 1980). Taken together, these mediating processes explain whether exposure to organizational events will result in positive or negative outcomes for performance (Lazarus, 1991b). To understand how organizational stress in sport may relate to the quality of one's outcomes, researchers have chiefly used cross-sectional designs to measure the organizational stressors that are encountered (Arnold, Edwards, \& Rees, 2018; Arnold, Fletcher, \& Daniels, 2016), how stressors are appraised (Bartholomew, Arnold, Hampson, \& Fletcher, 2017), responded to (Arnold \& Fletcher, 2015), and coped with (Arnold, Fletcher, \& Daniels, 2017) at single points in time.

The research literature to date, however, has typically neglected that transactional stress processes are episodic; therefore, their associations should be examined longitudinally (Didymus \& Fletcher, 2012; Fletcher \& Arnold, 2017; Larner, Wagstaff, Thelwell, \& Corbett, 2017; Lazarus, 1999; Roberts, Arnold, Turner, Colclough, \& Bilzon, 2019). Moreover, although cross-sectional evidence suggests that organizational stress processes are associated with subjective performance evaluations (Arnold et al., 2017, 2018; Britton, Kavanagh, \& Polman, 2019; Tamminen, Sabiston, \& Crocker, 2018), no studies to date have examined whether the ability to cope is associated with future proxy indicators of objective performance 
(e.g., playing time). Therefore, the first purpose of this study is to examine organizational stress processes over time. Using an experience sampling method (ESM; Hektner, Schmidt, \& Csikszentmihalyi, 2007), within-person associations of daily cognitive appraisals, affective responses, and coping methods are examined. The second purpose is to assess the association between coping with organizational events and future performance in a specific professional sport context.

\section{Conceptual Background and Hypotheses}

Lazarus' cognitive-motivational-relational theory asserts that stress is the result of three interacting processes: cognitive appraisals of events, affective responses, and coping (Lazarus, 1999). Cognitive appraisals of events are the evaluations a person makes in terms of the significance for one's affective well-being and goals (primary appraisal) and the evaluation of coping options (secondary appraisal). According to Lazarus and Folkman (1984), if events are perceived to be significant for well-being and goals, then events will be appraised as a threat, harm/loss, or challenge. Threat appraisals refer to the potential for damage; harm/loss appraisals represent damage which has already occurred; and challenge appraisals refer to the potential for progressing towards one's goals (Lazarus, 1991a). Despite the lack of research examining episodic appraisal-affect associations of organizational events in sport (Fletcher \& Arnold, 2017; Fletcher et al., 2006), evidence suggests that sport performers can appraise a range of organizational events as threatening (e.g., barriers to performing one's role), harmful (e.g., conflict with a teammate or coach) and challenging (e.g., rehabilitating from injury) towards attaining their goals (Didymus \& Fletcher, 2012; Hanton, Fletcher, \& Wagstaff, 2012; Rumbold, Fletcher, \& Daniels, 2018). Cognitive appraisals have also been found to mediate the relationship between organizational stressors (for a review, see Arnold \& Fletcher, 2012; Arnold, Fletcher, \& Daniels, 2013) and basic psychological needs (Bartholomew et al., 2017), and, basic needs are commonly linked to 
affective responses (Lazarus, 1999). Although a few studies have identified cross-sectional associations between cognitive appraisals and anxiety responses in the lead up to competition events (e.g., Quested, Bosch, Burns, Cumming, Ntoumanis, \& Duda, 2011; Martinent \& Ferrand, 2015), there is a theoretical case for examining appraisal-affect relationships within the context of organizational stress. In line with Lazarus' (1999) relational-meaning centered approach to understanding organizational stress, it was argued that research needs to examine the mediating processes and how they interact within the occupational contexts in which they occur, whilst also being cognisant of individual differences (Lazarus, 1999, p. 131).

Moreover, to further understand the explanatory potential of appraisals, it is important to assess how specific appraisals underlie affect and how this relationship may vary over time (Lazarus 1999).

Hypothesis 1: Threat and harm appraisals of organizational events will be associated with negative affect, whereas challenge appraisals will be associated with positive affect. In follow-up to this hypothesis, it is also important to consider how specific primary appraisals of organizational events initiate coping attempts. Indeed, Didymus and Fletcher (2014) found that appraisal of organizational demands and coping effectiveness appear to be linked to the coping behaviours employed. Furthermore, research in competition contexts (Dias, Cruz, \& Fonseca, 2012) has suggested that threat appraisals are associated with emotion-focused coping behaviours (e.g., venting of emotions). Coping however, has many features, including problem-focused and emotion-focused functions (Skinner, Edge, Altman, $\&$ Sherwood, 2003). One proactive form of emotion-focused coping is emotional-approach coping, which signifies the active expression of affect (Baker \& Berenbaum, 2007). We differentiate between coping functions and behaviours (Skinner et al., 2003), where coping functions are the intended goal of coping (problem-solved or affect expressed) and coping behaviours are enacted to fulfil those goals. In line with organizational psychology models of 
121 coping (Daniels, Beesley, Cheyne, \& Wismalasiri, 2008; Daniels, Beesley, Wimalasiri, \&

122 Cheyne, 2013; Daniels, Boocock, Glover, Hartley, \& Holland, 2009), we focus on problem-

123 and emotion-approach coping functions attempted through enacting behaviours targeted at the

124 execution of control or behaviours targeted at eliciting support. In line with transactional

125 stress theory, cognitive appraisals are likely to influence coping behaviours and functions

126 simultaneously, which govern the actions and goals of coping (Folkman, 2008).

127 Hypothesis 2: Appraisals of organizational events will be associated with problem-focused 128 and emotion-approach functions enacted by coping behaviours.

129 If appraisals are found to be associated with affective responses and coping, then it

130 follows that affective responses should also activate coping efforts (Lazarus, 1991a).

131 Research suggests that affect is linked to problem-focused and emotion-approach coping for

132 several reasons. Firstly, negative affect is traditionally linked to action tendencies through

133 fight or flight responses (Lazarus, 1999). Consequently, negative affect is associated with

134 increased attention to solve problems and attempts to control issues that may initially be

135 perceived as controllable (Folkman, 2008). Negative states may also initiate affective

136 information sharing to facilitate social thinking and reduce distress through venting or social

137 validation. Secondly, expressing positive affect with teammates may result in sustained

138 positive affect by establishing social bonds and adjusting team goals (Rimé, 2009). In contrast

139 to research in sport which links problem-focused coping with positive affect (Arnold et al.,

140 2017), we argue that positive affect is unlikely to lead to problem-focused coping since

141 positive affect represents satisfaction from progressing towards goal attainment (Lazarus \&

142 Folkman, 1984). Furthermore, individuals are unlikely to actively change aspects of their

143 organizational environment that they are satisfied with. Similarly, since the function of

144 problem-focused coping is to resolve or remove problems caused by events (Lazarus \&

145 Folkman, 1984), individuals are unlikely to seek resources to solve issues that they experience 
146 contentment from. In contrast, we would expect positive and negative affect to be associated

147 with emotion-approach coping because the intended goal of this form of coping is to actively

148 express positive affect whilst regulating negative affect (Baker \& Berenbaum, 2007).

149 Hypothesis 3: Negative affective responses will be associated with problem-focused and

150 emotion-approach coping, whereas positive affective responses will be associated with

151 emotion-approach functions.

152 Research in sport has been limited to measuring single episodes of coping and

153 subjective performance (Fletcher \& Arnold, 2017). Beal and colleagues (Beal, Weiss, Barros,

$154 \&$ MacDermid, 2005) assert that coping resources are allocated towards or away from tasks

155 when events support or prevent goal attainment, respectively. Hence, future performance

156 outcomes are influenced by the appropriate allocation of coping resources through enactment

157 of behaviours to complete performance tasks. Although appraisals and affective responses can

158 have direct or indirect effects on behaviour (and subsequently performance), behaviour is

159 typically the primary focus of a performance outcome, as action is the translation of thoughts

160 and feelings into something that is either effective or ineffective within our occupational

161 environment (Beal et al., 2005; Beal \& Weiss, 2013). Since coping behaviours can include

162 taking control or eliciting support to optimise goal progress (Daniels et al., 2013), we would

163 expect coping functions enacted by coping behaviours to be allied with greater attainment of

164 future performance goals. One of the ways in which coping may be related to long-term

165 performance in professional sport is playing time. From a talent identification perspective,

166 examining how coping may relate to future playing time aligns with recent calls to examine

167 the contribution of psychological attributes in improving predictions of future sport

168 performance (Den Hartigh, Niessen, Frencken, \& Meijer, 2018; Tredrea, Dascombe,

169 Sanctuary, \& Scanlan, 2017).

170 Hypothesis 4: Coping functions enacted by behaviours will be associated with future playing 
171 time.

The current study furthers research on organizational stress in sport in several ways.

173 Firstly, we examine the dynamism of mediating stress processes as they occur in a

174 professional sport context. We used an experience sampling method (ESM) to collect daily

175 diary data across a 5-week period, to provide greater accuracy than can be gained through

176 retrospective recall (Bolger, Davis, \& Rafaeli, 2003). Secondly, we controlled for a wide

177 range of within- (e.g., time, day) and between-person differences (e.g., personality, playing

178 position) given the potential influence of these variables on episodic processes (Lazarus,

179 1991a, 1999). Thirdly, we examined how coping during the daily diary period may be

180 associated with future playing time in professional sport.

$181 \quad$ Materials and Methods

182

183

184

185

186

187

188

189

190

191

192

193

194

195

\section{Research Design}

When utilising an experience sampling design, a number of methodological principles were followed. The methodology requires individuals and teams under investigation to be studied frequently (e.g., multiple daily assessments) over a relatively long period of time (e.g., a week or longer) in which performers naturally interact together within their organizational environment (Hektner et al., 2007). A key principle of this methodology is to accurately capture participant data as close as possible to when they occurred during the day (e.g., in the past hour). The benefit of this approach is that it reduces memory recall bias of events, perceptions, feelings and behaviours, which can occur through use of retrospective research designs (Bolger et al., 2003). Conducting multiple assessments of daily phenomena over a long period time enables researcher to examine within-person relationships whilst controlling for a series of contextual (e.g., time of day) and individual difference variables (e.g., stable appraisal patterns). ESM designs typically adopt event-contingent schedules (i.e., study variables are assessed immediately some class of events) which should attempt to mirror the 

217 illness/injury).

\section{Measures}

organizational context and daily events that commonly occur (Hektner et al., 2007). To achieve suitable power to detect meaningful relationships between appraisals, affective responses and coping, a single professional sports team was recruited for this purpose.

\section{Participants and Procedure}

At the beginning of the season, the academy manager of a professional rugby union team based in the United Kingdom was contacted and informed of the study aim. Following institutional ethical approval, parental and player consent, academy players were recruited via the manager's request for volunteers from the squad. The sample consisted of male rugby union players $(n=39)$ with an average age of 17.23 years $(S D=.87$, range $=16-19)$. At the time of recruitment, 6 of the 39 players had competed internationally at youth and / or junior level. Data were collected using Palm Tungsten personal digital assistants (PDAs). These handheld organisers are programmed to collect daily data whilst participants are operating within their organization. The PDAs administered questions twice daily over one training week (Monday-Friday), for a period of five weeks (ESM period). Due to the varied training schedule of the participants, the PDAs were programmed to 'run on command'. In this way, participants were asked to complete the PDAs at their academy organization in the morning and late afternoon between the hours of $10 \mathrm{am}$ and 5pm. Prior to the ESM period, a background questionnaire was distributed to participants, which assessed some control variables $^{1}$. At this time, participants were also given a presentation on how to use the PDAs and troubleshooting prior to them being distributed. Participants provided PDA data on 997 out of a possible 1880 occasions (after removing participants due to international selection or

\section{Cognitive appraisals during the ESM period} Participants were firstly asked to identify an academy-related (i.e., organizational) 
221 event $^{2}$ in the past hour that impacted on their role. In line with best practice principles for

222 experience sampling quantitative designs, the selection of these events were based on the

223 common daily events that were occurring within the sampled sport organization. In addition,

224 an hour time period was chosen to capture appraisal data as close as possible to when they

225 occur in the organizational environment and to reduce memory recall bias (Bolger et al.,

226 2003). Participants chose from one of the following: 'a conflict with another person', 'a

227 pleasant social interaction', 'barriers to performing your role', 'receiving social support',

228 'doing physically difficult work', 'doing mentally difficult work', or 'other'. Following this,

229 appraisals were assessed by asking participants to indicate the extent to which they rated an

230 academy-related event in the past hour as a threat, challenge, or harm. Following guidelines

231 for conducting ESM research (Bolger et al., 2003; Fisher \& To, 2012; Hektner et al., 2007),

232 single item measures for each appraisal were deemed acceptable, given the narrow time frame 233 that participants had to recall specific events.

234 Affective responses during the ESM period

235 Affective responses were assessed by asking players to rate in the past hour how they

236 felt in response to academy-related events. The four items that measured affect were anxiety,

237 anger, sadness, and happiness. These items were selected as they signify a basic set of core

238 relational states by which threat, harm, loss and challenge appraisals are theorized to be

239 associated (Lazarus \& Folkman, 1984; Power \& Dalgleish, 2008). Principal components

240 analysis revealed a two-dimensional solution. Thus, variables were split into negative and

241 positive affect. This is consistent with research that has identified negative and positive affect

242 as the major dimensions of affective well-being (Watson \& Clark, 1984). Negative affect

243 (NA; $\alpha=.71)$ was assessed with anxiety, anger, and sadness items. Positive affect (PA) was

244 assessed with happiness.

245 Coping functions and behaviours during the ESM period 
Coping was assessed by asking participants to rate how they coped with academy-

related events in the past hour. Two items were used to evaluate each form of problem-

248 focused and emotional-approach coping enacted by executing control over one's role or

249 eliciting support from others. These items were adapted from measures used in organizational

250 psychology research whereby the discriminant validity has been supported previously

251 (Daniels et al., 2009; 2013; 2014). In this study, executing control to solve problems (CHA-

252 SP; $\alpha=.76)$ measured the extent to which players changed aspects of their behaviour to solve 253 problems. Eliciting support to solve problems (DIS-SP; $\alpha=.86$ ) measured the degree to

254 which players discussed events with others to solve problems. Executing control to express

255 affect (CHA-EA; $\alpha=.71)$ measured the degree to which players changed tasks to allow them

256 to express affect. Eliciting support to express affect (TAL-EA; $\alpha=.80$ ) assessed the extent to

257 which players talked to others to express affect. All of the appraisal, affect and coping items

258 were rated on a five-point scale ( $1=$ 'Not at all', 5 = 'Very much so').

259 Control variables

A series of situational and dispositional variables were included as control variables.

261 According to Lazarus' stress theory, individual variability in affect and coping attempts may

262 be subject to ongoing changes over time. Therefore, the week (i.e., weeks 1-5), day (i.e.,

263 Monday to Friday) and time period (i.e., morning, afternoon) in which participants completed

264 the PDAs were dummy coded as within-person controls (e.g., 0 = 'not week 1', 1 = 'week 1').

265 In addition, Lazarus argued that individuals may hold stable styles of appraisal and affect,

266 which represent learned beliefs about the conjunction between what is occurring in the

267 environment and one's personality (Lazarus, 1991a, p. 192). Therefore, participants' average

268 levels for episodic appraisals and affect were included as between-person control variables.

269 Research has also shown that neuroticism and extraversion are strongly linked to

270 affect (Watson \& Clark, 1984) and coping (Allen, Greenlees, \& Jones, 2011). Thus, 
271

272

273

274

275

276

277

278

279

280

281

282

283

284

285

286

287

288

289

290

291

292

293

294

295

neuroticism and extraversion were included as between-person controls. The International

Personality Item Pool (IPIP: Goldberg et al., 2006) version of the revised NEO personality inventory (NEO-PI-R: Costa $\&$ McCrae, 1992) provided 20 items for both neuroticism $(\alpha=$ .94) and extraversion $(\alpha=.96)$. Participants rated the extent to which each item described them accurately on a five-point scale ( $1=$ 'strongly disagree', $5=$ 'strongly agree'). To assess the notion that situational contexts may shape a person's emotional responses and coping attempts (Lazarus, 1991a), participants' playing position ( $0=$ 'backs', 1 = 'forwards') and key decision makers in the playing squad $(0=$ 'not a key decision maker', $1=$ 'key decision maker') were dummy coded as between-person control variables. The manager and assistant coach identified five key decision makers from the squad who displayed leadership behaviours and made considerable decisions for the team.

Playing time

To assess the association between academy players' coping abilities during the ESM period and playing time at the senior professional level, an online database was used. The database (www.statbunker.com) supplies free-to-view performance data on professional rugby union players worldwide. In so far that rugby academies in the United Kingdom typically develop players up to the age of 21 , the average age of the participants during the ESM period $\left(\mathrm{M}_{\mathrm{age}}=17.23\right.$ years $)$ suggested that a 5-year lag would be appropriate to measure the extent to which these players had since played for senior professional rugby union teams. Therefore, total playing time data accrued over a 5-year period was collected 5 years post the rugby union season in which ESM data was collected. Playing time was measured by coding for the number of minutes played at the senior professional level 5 years post the ESM period.

\section{Data Analysis}

Multilevel regressions were conducted using Hierarchical Linear Modeling software with restricted maximum likelihood (HLM 7.01; Raudenbush et al., 2011). A two-level model 
was used to estimate the within-person associations between appraisals, affect and coping (Level 1), whilst accounting for within-person (Level 1) and between-person controls (Level 2). Robust standard errors were examined to ensure that any violations of the assumption of normality had not affected the results (Raudenbush et al., 2011). Consistent with recommendations to remove between-person variance from repeated measurements from the same people over time, all of the independent variables were person mean centered (i.e., centered within cluster, CWC; Enders \& Tofighi, 2007) in the level 1 equation with withinperson control variables (i.e., week, day, time), with regression slopes for the appraisal variables allowed to vary between people. Where the variability of regression slopes was not significantly different from zero, the slopes were fixed to be invariant across people. ${ }^{3}$

Between-person variance in the independent variables was represented by the average for each person across the ESM period. Between-person variables were then entered incrementally and grand mean centered at the overall mean (Enders \& Tofighi, 2007).

To assess hypothesis 4 , zero-inflated negative binomial regression was conducted using the 'ZEROINFL' R plug-in for SPSS to assess the longitudinal relationships between person-averaged coping measured during the ESM period and senior professional minutes played 5 years later. This method of regression is preferred over others (e.g., ordinary leastsquares, poisson) when the dependent variable has over-dispersion and contains a high proportion of zero counts (Yang, Harlow, Puggioni \& Redding, 2017).

\section{Results}

Table 1 shows the means, standard deviations, reliabilities, and correlations for the ESM, control and senior playing time variables respectively.

\section{Within-Person Appraisals and Affective Responses}

Table 2 shows the results of the multilevel regression analyses of appraisals on affective responses. ${ }^{4}$ Hypothesis 1 proposed that threat and harm appraisals would be 
associated with negative affect (NA), whereas challenge appraisals would be associated with positive affect $(\mathrm{PA})$. The findings revealed that threat $(B=0.22, p<.001)$ and harm appraisals $(B=0.25, p<.001)$ were strongly associated with NA. The appraisals accounted for $31 \%$ of the within-person variance. These results support the hypothesis whilst considering the role of within- and between-person differences. Person-averaged threat $(B=$ $0.54, p<.01)$ and harm appraisals $(B=0.38, p<.05)$ were also significantly related to NA. When investigating the relationships between appraisals and PA, it was found that challenge $(B=0.15, p<.01)$ and harm appraisals $(B=-0.10, p<.05)$ were both associated. The episodic appraisals accounted for $13.4 \%$ of the within-person variance. These results supported hypothesis 1 whilst controlling for within- and between-person differences. In addition, person-averaged challenge appraisals $(B=0.65, p<.001)$ were significantly related to PA.

\section{Within-Person Appraisals, Affective Responses and Coping}

Table 2 also shows the results of the multilevel regressions of appraisals and affective responses on coping. Hypothesis 2 proposed that appraisals would be significantly related to problem-focused and emotion-approach coping. In addition, hypothesis 3 proposed that NA would be related to both problem-focused and emotion-approach coping, whereas PA would only be associated with emotion-approach coping. Counter to hypothesis 2 , there were no significant associations between appraisals and executing control to solve problems (CHASP; $p$ range $=.08-.48)$. In support of hypothesis 3 , there was an association between NA and CHA-SP $(B=0.22, p<.001)$. Appraisals and affect accounted for $20.3 \%$ of the within-person variance, with $9.4 \%$ of this unique variance attributable to appraisals. Threat $(B=0.06, p<$ $.05)$ and challenge appraisals $(B=-0.06, p<.05)$ were associated with eliciting support to solve problems (DIS-SP). In relation to hypothesis 3, NA displayed a positive association with DIS-SP $(B=0.09, p<.01)$. In total, appraisals and affect accounted for $16.2 \%$ of the 
within-person variance.

When examining the regressions for appraisals and affect on emotion-approach coping, in support of hypothesis 2 , threat appraisals $(B=0.14, p<.01)$ were significantly associated with executing control to express affect (CHA-EA). Appraisals accounted for $15.1 \%$ of the within-person variance. In partial support of hypothesis 3 , NA $(B=0.20, p<$ .001) was significantly associated with CHA-EA but PA was not $(p=.16)$. Affective responses provided an additional 5.5\% of within-person variance. For eliciting support to express affect (TAL-EA), partial support for hypothesis 2 was found, whereby challenge appraisals were inversely associated $(B=-0.06, p<.01)$. In contrast, threat and harm appraisals were not associated $(p=.08)$. The appraisals accounted for $11.2 \%$ of the withinperson variance in TAL-EA. In addition, NA $(B=0.15, p<.001)$ and PA $(B=0.06, p<.05)$ were significantly associated with TAL-EA, although the additional within-person variance explained by the inclusion of affect was less than $1 \%$. These results supported hypothesis 3 whilst controlling for within- and between-person differences. Furthermore, both key decision makers $(B=1.24, p<.001)$ and the afternoon time period $(B=0.17, p<.01)$ were associated with eliciting support to express affect (TAL-EA).

\section{Between-Person Coping and Senior Playing Time}

Kendall's tau point-biserial correlations were conducted to determine the order in which person-averaged coping variables were entered into the regression model, as follows: (a) eliciting social support to solve problems (DIS-SP; $\tau=.21, p<.10$ ), (b) executing control to solve problems (CHA-SP; $\tau=.14, p>.10)$, (b), (c) executing control to regulate emotions (CHA-EA; $\tau=.14, p>.10$ ), and (d) eliciting social support to regulate emotions (TAL-EA; $\tau$ $=.09, p>.10)$. Zero-inflated negative binomial regression indicated that eliciting social support to solve problems (DIS-SP; $B=-2.37, z=-2.20, p<0.05$ ) and eliciting social support to regulate emotions (TAL-EA; $B=1.50, z=1.91, p=0.05$ ) were both significantly 
associated senior minutes played, whilst other coping variables were not associated. These results provide partial support for hypothesis 4; players reporting lower levels of eliciting social support to solve problems (DIS-SP) and higher levels of eliciting social support to regulate emotions (TAL-EA) respectively during the ESM period were more likely to play a greater number of minutes 5 years later at the senior professional level.

\section{Discussion}

This study extends understanding of: (a) how daily cognitive appraisals of organizational events relate to affect, (b) how appraisals and affective responses relate to coping functions through behaviours, and (c) how coping relates to future performance. Consistent with stress appraisal frameworks (Lazarus, 1991a; 1999), hypothesis 1 was supported in highlighting that positive affect (PA) may be experienced when events are appraised as a challenge to progress towards one's goals and when events are not appraised as harmful to one's goal progress. Moreover, negative affect (NA) may be experienced when events are perceived as threatening or harmful.

Partial support was found for the second hypothesis, whereby threat appraisals were positively related to eliciting support to solve problems (DIS-SP) and executing control to express affect (CHA-EA). Additionally, challenge appraisals were inversely associated with DIS-SP and eliciting support to express affect (TAL-EA). To explain these findings, secondary appraisals of available resources and controllability may direct effort towards solving the appraisal of an event, or allocating resources to regulate feelings (Beal et al., 2005; Lazarus, 1999). It is conceivable, therefore, that high levels of threat may lead to taking control over tasks to change or sustain affect, particularly when perceptions of controllability are high (Didymus \& Fletcher, 2014). In comparison, when perceptions of control are low, then threat appraisals may lead to sharing feelings with others. 
hypothesis 3 such that NA was strongly related to all coping subscales. In addition, PA was significantly associated with eliciting support to express affect (TAL-EA). These results support organizational psychology research in emphasizing that individuals concurrently employ a range of control and support seeking behaviours to solve problems and express affect (Daniels et al., 2009; 2013, Daniels, Glover \& Mellor, 2014). Previous stress literature indicates that active problem solving designed to control the situation (i.e., CHA-SP) is typically adopted when events are initially perceived as controllable (Folkman, 2008).

Moreover, controlling behaviours that involve temporarily removing oneself to vent or sustain positive affect (i.e., CHA-EA) may be constructive in restoring previously depleted resources (Beal et al., 2005). Talking to team members to express affect (i.e., TAL-EA) may also serve an important function for regulating NA and PA in organizations. In accordance with Rimé (2009), sharing affect with others could enhance social bonds through the celebration and reorganization of team goals, which in turn may help to regulate affect.

In accordance with Beal et al. (2005), hypothesis 4 found that eliciting support to solve problems (DIS-SP; inversely) and eliciting support to express affect (TAL-EA) were significantly associated with senior minutes played. DIS-SP and TAL-EA both signify eliciting support and communicating with others about improving individual and team performance through problem solving or regulating affect (Daniels et al., 2013). The positive relationship with TAL-EA would suggest that talking about how one feels in a team environment encourages others to talk about their feelings. This social sharing of affect can strengthen empathic understanding, unity and reciprocal liking (Rimé, 2009). Such behaviours are likely to represent favourable citizenship behaviours, which combined with evaluations of game performance may be linked to selection decisions in professional sport (Whiting \& Maynes, 2016). On the basis that key decision makers reported higher levels of eliciting support to solve problems and express affect (i.e., DIS-SP and TAL-EA) during the 
ESM period, this would suggest that key players in the academy team perceived eliciting support as an important behaviour to enact to facilitate being selected.

Previous research linking coping and sport performance has used subjective evaluations as a means of exploring relationships with performance (e.g., Arnold et al., 2017, 2018; Didymus \& Fletcher, 2017). From a talent development perspective, playing time may not only offer an additional method of assessing future performance attainment (Tredrea et al., 2017), but may capture a novel indication of successful athlete adaptation, since the goal of professional academies is to facilitate successful transitions to the senior level (Rothwell, Rumbold, \& Stone, 2019). In this regard, future selection decisions (i.e., playing time) may be influenced by players' consistent and fluctuating tendencies to use coping resources enacted by eliciting support to complete performance tasks in training environments. With support and cooperation being key to team functioning, managers and head coaches are likely to value players who demonstrate these coping attributes, to aid the creation and maintenance of a high-performing cohesive team (Whiting \& Maynes, 2016).

\section{Strengths, Limitations and Future Research Directions}

A strength of the study was the use of experience sampling methods (ESM) to provide ecologically valid information on the organizational stress processes that vary over time within a professional sport environment. Using innovative electronic diaries allowed for greater measurement accuracy than other field research measures and can improve power estimates by providing a large number of daily observations (Bolger et al., 2003). However, although ESM procedures have the advantage of collecting data in ecologically valid settings, the varied training schedule of the rugby players precluded the ability to programme alerts in to the personal digital assistants to remind the players to complete the questionnaires at fixed time points during the day; which may have affected our compliance rate. Future researchers interested in applying experience sampling methodology are encouraged to identify proactive 
446 and technical ways to remind participants to regularly complete diary data. Although the

447 sample size was small in this study, power was not an issue for the main purpose, as the unit

448 of analysis was the daily assessment of organizational stress processes $(k=698)$.

449 Future research could develop these efforts by examining how organizational stress

450 processes fluctuate within a sport team throughout a season. In addition, researchers should

451 continue to test the influence of appraisals and affective responses in predicting a wider range

452 of coping functions enacted by behaviours. Future studies also need to improve the causality

453 of our claims that specific coping functions enacted by behaviours may be associated with

454 future performance. An appropriate way to extend our findings would be to measure coping

455 more regularly on an annual basis. Professional sport is suitable for testing these relationships,

456 as the digital availability of performance data is naturally occurring (Whiting \& Maynes,

457 2016). From an applied perspective, this study suggests that organizational stress management

458 programmes may be important for improving adaptation to threatening or harmful

459 environments. Surprisingly, the evaluation of these interventions in sport is in its infancy

460 (Didymus \& Fletcher, 2017; Fletcher \& Arnold, 2017; Rumbold, Fletcher, \& Daniels, 2012,

461 2018). Coaches, sport scientists and practitioners operating in sport organizations should

462 encourage transitioning players to develop planned responses to potentially threatening or

463 harmful situations, to promote proactive coping efforts. This encouragement needs to be

464 accompanied with an awareness of potential personal (e.g., stable appraisals, personality) and

465 situational factors (e.g., key decision makers) that may influence players' appraisal and coping

466 tendencies. In the context of the present sample, developing coping resources and behaviours

467 will benefit those individuals who continually need to adapt in professional sport academies.

468 Specifically, eliciting support from teammates and staff who operate in the same sport

469 organization should be encouraged. Performers should also be educated on the individual and

470 team benefits that may ensue from seeking support to solve problems and regulate affect. 


\section{Conclusion}

In conclusion, this study makes a unique contribution to theoretical and empirical knowledge of organizational stress in the context of professional sport. Our study highlights how daily cognitive appraisals measured over a five-week period relate to daily affective responses. Secondly, we highlight how daily appraisals and affective responses relate to daily coping. In doing so, this is one of the first studies in sport to examine a vast range of withinand between-group differences to explain how sport performers may respond to and cope with organizational events. To our knowledge, this study is also one of the first to assess how coping in high-level junior athletes is associated with future proxy indicators of objective performance, namely, minutes played at the senior professional level. In supporting calls to examine how psychological attributes may explain future performance (Den Hartigh et al., 2018; Tredrea et al., 2017), our findings suggest that eliciting support to solve problems and regulate affect within academy environments may be linked to future playing time at the senior professional level.

\section{Declaration of interest}

The authors report no conflict of interest.

\section{Footnote}

1. A copy of the background questionnaire is available from the first author on request.

2. By 'event', we refer to characteristics of a specific organizational environment that influence a person's experience of thoughts, feelings and behaviours (Beal \& Weiss, 2013). Although the term may be compared with the terms 'demands' and 'stressors', events represent a broader definition by which a range of environmental variables encapsulate daily demands, social constraints and opportunities (Lazarus, 1999, p. 63). Events relevant to the specific organizational environment in this study were identified in consultation between the first author and the academy staff in a staff meeting that occurred prior to the data collection period. 3. An incremental forward stepwise approach was adopted to check for significant variation in regression slopes at level 1. For example, to test hypothesis 1, negative affect was entered as the level 1 outcome, and all appraisals were person mean centered (CWC) as the level 1 independent variables. Within-person control variables (e.g., week, day, time) were all entered prior to the inclusion of independent variables and left in their raw metric form. For each equation, level 1 slopes were initially allowed to vary across individuals (i.e., random slopes). Where slopes had non-significant variance components $(p<.10)$ or low reliabilities $(<.05)$, they were fixed to be invariant across participants (Raudenbush et al., 2011). This step was then repeated to check for 
502 further invariance in slopes. This approach was continued until only random slopes were left to vary between 503 participants in the equation at that step. Following this step, between-person control variables were entered 504 incrementally at level 2: (a) person-averaged threat appraisals, (b) person-averaged challenge appraisals, (c) 505 person-averaged harm appraisals, (d) person-averaged negative affect, (e) person-averaged positive affect, (f) 506 neuroticism, (g) extraversion, (h) key decision makers, and (i) playing position. All control variables were grand 507 mean centered at the overall mean of the participant sample to provide meaning to the intercept.

508 4. To check for the robustness of results, we examined each hypothesis by comparing two regression models.

509 The first model $(n=39, d f=997)$ included level 2 control variables (i.e., averaged appraisals and affect,

510 neuroticism and extraversion, key decision makers and playing position). In comparison, the second model ( $n=$ $51128, d f=698$ ) included level 1 control variables (i.e., week, day, time) in addition to the level 2 controls. In all 512 cases, the hypotheses were supported. However, because some level 1 controls were significantly associated 513 with affect and coping variables, it was decided to accept the hypotheses based on the findings presented from 514 the second model. 


\section{References}

Allen, M. S., Greenlees, I., \& Jones, M. (2011). An investigation of the five-factor model of personality and coping behaviour in sport. Journal of Sports Sciences, 29, 841-850. doi: 10.1080/02640414.2011.565064

Arnold, R., Edwards, T., \& Rees, T. (2018). Organizational stressors, social support, and implications for subjective performance in high-level sport. Psychology of Sport and Exercise, 39, 204-212. doi: 10.1016/j.psychsport.2018.08.010

Arnold, R. S., \& Fletcher, D. (2012). A research synthesis and taxonomic classification of the organizational stressors encountered by sport performers. Journal of Sport and Exercise Psychology, 34, 397-429.

Arnold, R., \& Fletcher, D. (2015). Confirmatory factor analysis of the sport emotion questionnaire in organizational environments. Journal of Sports Sciences, 33, 169-179. doi: 10.1080/02640414.2014955520

Arnold, R., Fletcher, D., \& Daniels, K. (2013). Development and validation of the Organizational Stressor Indicator for Sport Performers (OSI-SP). Journal of Sport and Exercise Psychology, 35(2), 180-196.

Arnold, R., Fletcher, D., \& Daniels, K. (2016). Demographic differences in sport performers' experiences of organizational stressors. Scandinavian Journal of Medicine and Science in Sports, 26, 348-358. doi: 10.1111/sms.12439

Arnold, R., Fletcher, D., \& Daniels, K. (2017). Organizational stressors, coping, and outcomes in competitive sport. Journal of Sports Sciences, 35, 694-703.

Baker, J. P., \& Berenbaum, H. (2007). Emotional approach and problem-focused coping: A comparison of potentially adaptive strategies. Cognition and Emotion, 21, 95-118. doi: 10.1080/02699930600562276

Bartholomew, K. J., Arnold, R., Hampson, R. J., Fletcher, D. (2017). Organizational stressors and basic psychological needs: The mediating roles of athletes' appraisal mechanisms. Scandinavian Journal of Medicine and Science in Sports, 1-13, doi: 10.1111/sms.12851

Beal, D. J., \& Weiss, H. M. (2013). The episodic structure of life at work. In A. B. Bakker \& K. Daniels (Eds.), A day in the life of a happy worker (pp. 8-24). Hove: Psychology Press.

Beal, D. J., Weiss, H. M., Barros, E., \& MacDermid, S. M. (2005). An episodic process model of affective influences on performance. Journal of Applied Psychology, 90, 1054-1068. doi: 10.1037/0021-9010.90.6.1054 
Bolger, N., Davis, A., \& Rafaeli, E. (2003). Diary methods: Capturing life as it is lived. Annual Review of Psychology, 54, 579-616.

Britton, D. M., Kavanagh, E. J., \& Polman, R. C. J. (2019). A path analysis of adolescent athletes' perceived stress reactivity, competition appraisals, emotions, coping, and performance satisfaction. Frontiers in Psychology, 10: 1151. Doi: 10.3389/fpsyg.2019.01151

Costa, P. T., Jr., \& McCrae, R. R. (1992). Revised NEO Personality Inventory (NEO-PI$R$ ) and NEO Five-Factor Inventory (NEO-FFI) professional manual. Odessa, FL: Psychological Assessment Resources.

Daniels, K., Beesley, N., Cheyne, A., \& Wismalasiri, V. (2008). Coping processes linking the demands-control-support model, affect and risky decisions at work. Human Relations, 61, 845-874. doi: 10.1177/0018726708093543

Daniels, K., Beesley, N., Wimalasiri, V., \& Cheyne, A. (2013). Problem solving and well-being: Exploring the instrumental role of job control and social support. Journal of Management, 39, 1016-1043. doi:10.1177/0149206311430262

Daniels, K., Boocock, G., Glover, J., Hartley, R., \& Holland, J. (2009). An experience sampling study of learning, affect, and the demands control support model. Journal of Applied Psychology, 94, 1003-1017. doi: $10.1037 / \mathrm{a} 0015517$

Daniels, K., Glover, J., \& Mellor, N. (2014). An experience sampling study of expressing affect, daily affective well-being, relationship quality, and perceived performance. Journal of Occupational and Organizational Psychology, 87, 781805. doi: 10.1111/joop.12074

Den Hartigh, R. J. R., Niessen, A. S. M., Frencken, W. G. P., \& Meijer, R. R. (2018). Selection procedures in sports: Improving predictions of athletes' future performance. European Journal of Sport Science, 18, 1191-1198.

Dias, C., Cruz, J. F., \& Fonseca, A. M. (2012). The relationship between multidimensional competitive anxiety, cognitive threat appraisal, and coping strategies: A multi-sport study. International Journal of Sport and Exercise Psychology, 10, 52-65. Doi: 10.1080/1612197X.2012.645131

Didymus, F. F., \& Fletcher, D. (2012). Getting to the heart of the matter: A diary study of swimmers' appraisals of organisational stressors. Journal of Sports Sciences, 30(13), 1375-1385. doi: 10.1080/02640414.2012.709263 
Didymus, F. F., \& Fletcher, D. (2014). Swimmers' experiences of organizational stress: Exploring the role of cognitive appraisal and coping strategies. Journal of Clinical Sport Psychology, 8, 159-183.

Didymus, F. F., \& Fletcher, D. (2017). Organizational stress in high-level field hockey: Examining the transactional pathways between stressors, appraisals, coping and performance satisfaction. International Journal of Sports Science and Coaching, 12(2), 252-263. doi: 10.1177/1747954117694737

Enders, C. K., \& Tofighi, D. (2007). Centering predictor variables in cross-sectional multilevel models: A new look at an old issue. Psychological Methods, 12, 121138. doi: 10.1037/1082-989X.12.2.121

Field, A. (2013). Discovering statistics using IBM SPSS statistics. Thousand Oaks, CA: Sage.

Fisher, C. D., \& To, M. L. (2012). Using experience sampling methodology in organizational behaviour. Journal of Organizational Behaviour, 33, 865-877.

Fletcher, D., \& Arnold, R. (2017). Stress in sport: The role of the organizational environment. In Wagstaff, C. R. D. (Ed.), An organizational psychology of sport: Key issues and practical applications (pp. 83-100). Abingdon: Routledge.

Fletcher, D., Hanton, S., \& Mellalieu, S. D. (2006). An organizational stress review: Conceptual and theoretical issues in competitive sport. In S. Hanton \& S. D. Mellalieu (Eds.), Literature reviews in sport psychology (pp. 321-373). Hauppauge, NY: Nova Science.

Folkman, S. (2008). The case for positive emotions in the stress process. Anxiety, Stress, \& Coping: An International Journal, 21, 3-14.

Folkman, S., \& Lazarus, R. S. (1980). An analysis of coping in a middle-aged community sample. Journal of Health and Social Behavior, 21, 219-239.

Fouad, N. A., \& Bynner, J. (2008). Work transitions. American Psychologist, 63, 241241. doi: 10.1037/003-066X.63.4.241

Goldberg, L. R., Johnson, J. A., Eber, H. W., Hogan, R., Ashton, M. C., Cloninger, C. R., \& Gough, H. C. (2006). The International Personality Item Pool and the future of public-domain personality measures. Journal of Research in Personality, 40, 84-96. doi:10.1016/j.jrp.2005.08.007

Hanton, S., Fletcher, D., \& Wagstaff, C. R. D. (2012). Cognitive appraisals of stressors encountered in sport organizations. International Journal of Sport and Exercise 
Psychology, 10(4), 276-289. doi: 10.1080/1612197X.2012.682376

Hektner, J. M., Schmidt, J. A., \& Csikszentmihalyi, M. (2007). Experience sampling method: Measuring the quality of everyday life. Thousand Oaks, CA: Sage.

Hofmann, D. A., \& Gavin, M. B. (1998). Centering decisions in hierarchical linear models: Implications for research in organizations. Journal of Management, 24, 623-641.

Karasek, R. A., \& Theorell, T. (1990). Healthy work: Stress, productivity and the reconstruction of working life. New York, NY: Basic Books.

Larner, R. J., Wagstaff, C. R. D., Thelwell, R. C., \& Corbett, J. (2017). A multistudy examination of organizational stressors, emotional labor, burnout, and turnover in sport organizations. Scandinavian Journal of Medicine \& Science in Sports, 27, 2103-2115. doi: 10.1111/sms. 12833

Lazarus, R. S. (1991a). Emotion and adaptation. New York, NY: Oxford University Press.

Lazarus, R. S. (1991b). Psychological stress in the workplace. In P. L. Perrewé (ed.), Handbook on Job Stress [special issue]. Journal of Social Behaviour and Personality, 6, 1-13.

Lazarus, R. S. (1999). Stress and emotion: A new synthesis. New York, NY: Springer.

Lazarus, R. S., \& Folkman, S. (1984). Stress, appraisal and coping. New York, NY: Springer.

Martinent, G., \& Ferrand, C. (2015). A field study of discrete emotions: Athletes' cognitive appraisals during competition. Research Quarterly for Exercise and Sport, 86, 51-62. Doi: 10.1080/02701367.2014.975176

Power, M., \& Dalgleish, T. (2008). Cognition and emotion: From order to disorder. Hove, UK: Psychology Press.

Quested, E., Bosch, J. A., Burns, V. E., Cumming, J., Ntoumanis, N., \& Duda, J. L. (2011). Basic psychological need satisfaction, stress-related appraisals, and dancers' cortisol and anxiety responses. Journal of Sport and Exercise Psychology, 33, 828-846.

Raudenbush, S. W., Bryk, A. S., Cheong, A. S., Fai, Y. F., Congdon, R. T., \& du Toit, M. (2011). HLM 7: Hierarchical linear and nonlinear modeling. Lincolnwood, IL: Scientific Software International.

Rimé, B. (2009). Emotion elicits the social sharing of emotion: Theory and empirical review. Emotion Review, 1, 60-85. doi: 10.1177/1754073908097189 
Roberts, G. A., Arnold, R., Turner, J. E., Colclough, M., \& Bilzon, J. (2019). A longitudinal examination of military veterans' invictus games stress experiences. Frontiers in Psychology, 10: 1934-. doi: 10.3389/fpsyg.2019.01934

Rothwell, M., Rumbold, J. L., \& Stone, J. A. (2019). Exploring British adolescent rugby league players' experiences of professional academies and dropout. International Journal of Sport and Exercise Psychology, doi: 10.1080/1612197X.2018.1549579

Rumbold, J. L., Fletcher, D., \& Daniels, K. (2012). A systematic review of stress management interventions with sport performers. Sport, Exercise, \& Performance Psychology, 1, 173-193. doi: 10.1037/a0026628

Rumbold, J. L., Fletcher, D., \& Daniels, K. (2018). Using a mixed method audit to inform organizational stress management interventions in sport. Psychology of Sport and Exercise, 35, 27-38. doi: 10.1016/j.psychsport.2017.10.010

Skinner, E. A., Edge, K., Altman, J., \& Sherwood, H. (2003). Searching for the structure of coping: A review and critique of category systems for classifying ways of coping. Psychological Bulletin, 129, 216-269.

Tamminen, K. A., Sabiston, C. M., \& Crocker, P. R. E. (2018). Perceived esteem support predicts competitive appraisals and performance satisfaction among varsity athletes: A test of organizational stressors as moderators. Journal of Applied Sport Psychology, doi: 10.1080/10413200.2018.1468363

Tredrea, M., Dascombe, B., Sanctuary, C. E., \& Scanlan, A. T. (2017). The role of anthropometric, performance and psychological attributes in predicting selection into an elite development programme in older adolescent rugby league players. Journal of Sports Sciences, 35, 1897-1903. doi: 10.1080/02640414.2016.1241418

Watson, D., \& Clark, L. A. (1984). Negative affectivity: The disposition to experience negative affective states. Psychological Bulletin, 96, 465-490.

Whiting, S. W., \& Maynes, T. D. (2016). Selecting team players: Considering the impact of contextual performance and workplace deviance on selection decisions in the national football league. Journal of Applied Psychology, 101, 484-497. doi: 10.1037/ap10000067

Yang, S., Harlow, L. I., Puggioni, G., \& Redding, C. A. (2017). A comparison of different methods of zero-inflated data analysis and an application in health surveys. Journal of Modern Applied Statistical Methods, 16(1), 518-543. doi: 10.22237/jmasm/1493598600 
Table 1. Means, Standard Deviations, Internal Consistencies, and Correlations

\begin{tabular}{|c|c|c|c|c|c|c|c|c|c|c|c|c|c|c|c|c|c|}
\hline & $M$ & $S D$ & $\alpha$ & 1 & 2 & 3 & 4 & 5 & 6 & 7 & 8 & 9 & 10 & 11 & 12 & 13 & 14 \\
\hline 1. Threat appraisals & 1.67 & 0.48 & - & - & .04 & .42 & .52 & -.11 & .27 & .22 & .37 & .28 & & & & & \\
\hline 2. Challenge appraisals & 3.19 & 0.88 & - & -.02 & - & -.02 & .06 & .34 & .02 & -.03 & .08 & .04 & & & & & \\
\hline 3. Harm appraisals & 1.52 & 0.49 & - & .55 & -.16 & - & .47 & -.18 & .32 & .23 & .29 & .22 & & & & & \\
\hline 4. NA & 1.72 & 0.48 & .71 & .62 & -.06 & .57 & - & -.22 & .35 & .24 & .36 & .28 & & & & & \\
\hline 5. PA & 3.24 & 0.78 & - & -.16 & .45 & -.25 & -.14 & - & -.05 & .01 & -.02 & .07 & & & & & \\
\hline 6. CHA-SP & 1.49 & 0.66 & .76 & .28 & .07 & .40 & .31 & -.06 & - & .57 & .57 & .45 & & & & & \\
\hline 7. DIS-SP & 1.60 & 0.71 & .85 & .20 & .08 & .29 & .24 & .08 & .55 & - & .40 & .61 & & & & & \\
\hline 8. CHA-EA & 1.75 & 0.67 & .64 & .27 & .05 & .33 & .29 & .02 & .62 & .41 & - & .54 & & & & & \\
\hline 9. TAL-EA & 1.94 & 0.76 & .78 & .23 & .15 & .22 & .30 & .16 & .40 & .59 & .51 & - & & & & & \\
\hline 10. Neuroticism & 2.21 & 0.63 & .94 & .22 & .02 & .19 & .21 & -.15 & .13 & -.05 & .14 & -.00 & - & & & & \\
\hline 11. Extraversion & 3.08 & 0.81 & .96 & .10 & .02 & .23 & .08 & -.00 & .16 & .11 & .15 & .08 & .00 & - & & & \\
\hline 12. KDM & 0.13 & 0.34 & - & -.05 & .00 & -.06 & -.01 & .32 & .03 & .23 & .14 & .20 & .00 & -.09 & - & & \\
\hline 13. Playing position & 0.56 & 0.50 & - & .17 & -.15 & .40 & .17 & -.27 & .17 & .11 & .21 & .17 & .00 & .18 & -.13 & - & \\
\hline 14. Playing Time & 0.51 & 0.51 & - & .06 & -.11 & -.01 & -.04 & -.02 & .14 & .21 & .14 & .09 & -.04 & .05 & .22 & -.03 & - \\
\hline
\end{tabular}

Note. $N=39 ; N$ of observations $=997 . \mathrm{NA}=$ negative affect; $\mathrm{PA}=$ positive affect; $\mathrm{CHA}-\mathrm{SP}=$ executing control to solve problems; DIS-SP $=$ eliciting support to solve problems; CHA-EA = executing control to express affect; TAL-EA = eliciting support to express affect; KDM = key decision makers. Correlations aggregated for the experience sampling methodology (ESM) and control variable data are shown below the main diagonal. Correlations for the experience sampling method (ESM) are above the main diagonal. $r>|.23|, p<.05, r>|.30|, p \leq .01$. Significance tests (2-tailed) are not shown for ESM data because of non-independence of observations. 
Table 2. Multilevel Regressions of Appraisals, Affective Responses and Coping

\begin{tabular}{|c|c|c|c|c|c|c|c|c|c|c|c|c|}
\hline & \multicolumn{2}{|c|}{ NA } & \multicolumn{2}{|c|}{ PA } & \multicolumn{2}{|c|}{ CHA-SP } & \multicolumn{2}{|c|}{ DIS-SP } & \multicolumn{2}{|c|}{ CHA-EA } & \multicolumn{2}{|c|}{ TAL-EA } \\
\hline Threat appraisals & 0.22 & $6.13^{* * *}$ & -0.11 & -0.73 & 0.04 & 1.74 & 0.06 & $2.24 *$ & 0.14 & $3.31 * *$ & 0.08 & 1.81 \\
\hline Challenge appraisals & 0.03 & 1.09 & 0.15 & $3.09 * *$ & -0.03 & -1.82 & -0.06 & $-2.37 *$ & 0.03 & 1.03 & -0.06 & $-2.64 * *$ \\
\hline Harm appraisals & 0.25 & $4.73^{* * * *}$ & -0.10 & $-1.94 *$ & 0.03 & 0.72 & 0.09 & 1.63 & 0.02 & 0.52 & 0.10 & 1.83 \\
\hline NA & - & - & - & - & 0.22 & $3.90^{* * *}$ & 0.09 & $2.54 * *$ & 0.20 & $3.93 * * *$ & 0.15 & $3.27 * * *$ \\
\hline${ }^{\mathrm{c}}$ Threat appraisals averaged & 0.54 & $3.47 * *$ & -0.54 & -1.30 & -0.18 & -0.50 & -0.28 & -0.56 & 0.55 & 1.43 & 0.26 & 0.48 \\
\hline${ }^{\mathrm{c}}$ Challenge appraisals averaged & 0.03 & 0.72 & 0.65 & $5.81 * * *$ & 0.12 & 1.05 & 0.27 & 1.69 & 0.10 & 0.80 & 0.23 & 1.37 \\
\hline${ }^{\mathrm{c}}$ Harm appraisals averaged & 0.38 & $2.13^{*}$ & 0.33 & 0.69 & 0.73 & 1.93 & 0.64 & 1.29 & 0.34 & 0.85 & 0.03 & 0.05 \\
\hline${ }^{\mathrm{c}} \mathrm{NA}$ averaged & - & - & - & - & -0.06 & -0.14 & -0.02 & -0.04 & -0.25 & -0.59 & 0.08 & 0.14 \\
\hline${ }^{\mathrm{c}} \mathrm{PA}$ averaged & - & - & - & - & -0.00 & -0.02 & -0.02 & -0.10 & 0.01 & 0.04 & -0.08 & -0.39 \\
\hline${ }^{\mathrm{c}}$ Playing position & 0.03 & 0.32 & -0.34 & -1.48 & 0.00 & 0.03 & -0.10 & -0.45 & 0.32 & 1.84 & 0.39 & 1.62 \\
\hline${ }^{\mathrm{c}}$ Week 1 & 0.16 & $1.97^{*}$ & 0.40 & $2.92 * *$ & 0.01 & 0.10 & -0.09 & -1.18 & 0.03 & 0.39 & -0.04 & -0.40 \\
\hline${ }^{\mathrm{c}}$ Week 2 & 0.06 & 0.67 & 0.28 & $1.93^{*}$ & 0.05 & 0.70 & 0.02 & 0.29 & 0.05 & 0.61 & -0.04 & -0.35 \\
\hline${ }^{\mathrm{c}}$ Week 3 & 0.10 & 1.18 & 0.38 & $2.63 * *$ & -0.02 & -0.28 & -0.01 & -0.18 & -0.01 & -0.10 & -0.00 & -0.00 \\
\hline${ }^{c}$ Week 4 & 0.04 & 0.53 & 0.29 & $2.06^{*}$ & 0.12 & 1.84 & 0.04 & 0.55 & -0.06 & -0.70 & 0.06 & 0.58 \\
\hline${ }^{\mathrm{c}}$ Week 5 & 0.09 & 1.08 & 0.31 & $2.15^{*}$ & 0.08 & 1.13 & 0.05 & 0.57 & -0.02 & -0.21 & 0.02 & 0.16 \\
\hline${ }^{\mathrm{c}}$ Monday & -0.39 & -0.68 & 1.67 & 1.62 & 0.05 & 0.10 & 0.26 & 0.45 & 0.11 & 0.18 & 0.22 & 0.29 \\
\hline${ }^{c}$ Tuesday & -0.51 & -0.89 & 1.50 & 1.46 & 0.03 & 0.06 & 0.24 & 0.42 & 0.05 & 0.08 & 0.16 & 0.22 \\
\hline
\end{tabular}




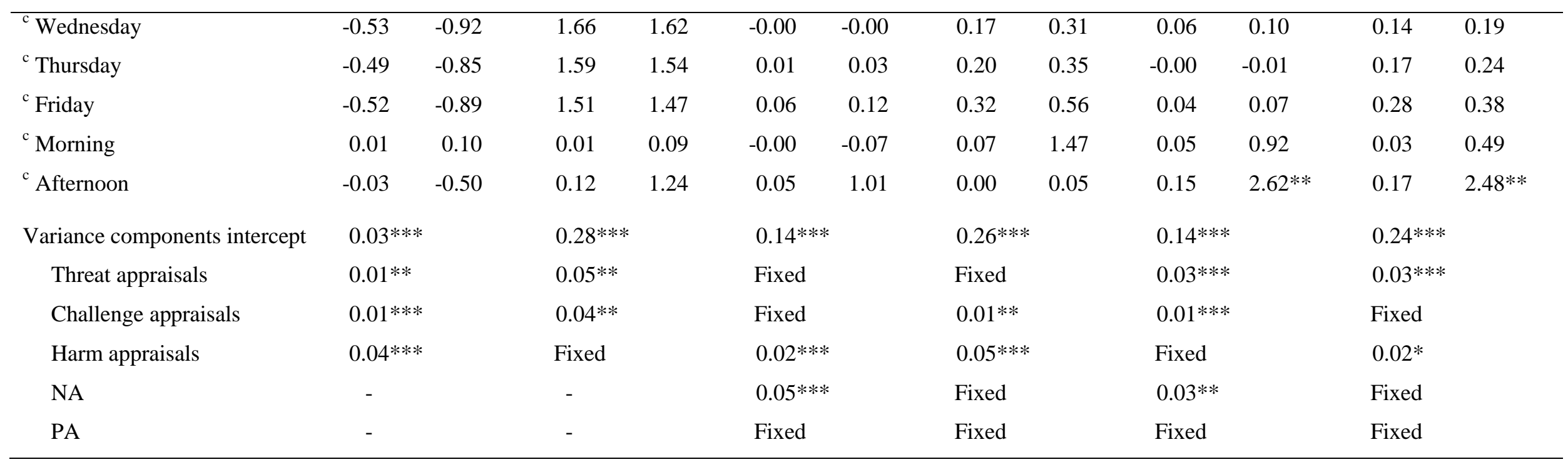

Note. $N=28$, number of observations $=698 .^{\circ}=$ control variables. Averaged values are between-person participant variables. NA $=$ negative affect; PA $=$ positive affect; CHA-SP = executing control to solve problems; DIS-SP = eliciting support to solve problems; CHA-EA = executing control to express affect; TAL-EA $=$ eliciting support to express affect. $* p \leq .05, * * p \leq .01, * * * p \leq .001$. 